\author{
Abstracta Iranica \\ Abstracta Iranica Revue bibliographique pour le domaine irano-aryen \\ Volume 32-33 | 2013 \\ Comptes rendus des publications de 2009-2010
}

\title{
Fatemeh Etemad. Undercounting Women's work in Iran
}

Yoko Suzuki

\section{OpenEdition}

1 Journals

\section{Édition électronique}

URL : http://journals.openedition.org/abstractairanica/41035

DOI : 10.4000/abstractairanica.41035

ISSN : 1961-960X

Éditeur :

CNRS (UMR 7528 Mondes iraniens et indiens), Éditions de l'IFRI

\section{Édition imprimée}

Date de publication : 1 décembre 2013

ISSN : 0240-8910

\section{Référence électronique}

Yoko Suzuki, « Fatemeh Etemad. Undercounting Women's work in Iran », Abstracta Iranica [En ligne], Volume 32-33 | 2013, document 453, mis en ligne le 01 juillet 2016, consulté le 27 septembre 2020. URL : http://journals.openedition.org/abstractairanica/41035; DOI : https://doi.org/10.4000/ abstractairanica. 41035

Ce document a été généré automatiquement le 27 septembre 2020.

Tous droits réservés 
Fatemeh Etemad. Undercounting Women's work in Iran

Yoko Suzuki 


\section{RÉFÉRENCE}

Fatemeh Etemad. « Undercounting Women's work in Iran ». Iranian Studies, Special issue: On gender and sexuality. Vol. 42, n 1, February 2009, p. 81-96.

1 Cet article met en question le marché caché (informel) des «actifs féminins » en Iran. Appuyée sur les résultats des enquêtes menées en 2001 au nord de Téhéran auprès de 350 femmes à l'âge actif, l'A. constate, à la différence des statistiques officielles de 2006 où le taux des actifs féminins n'atteint que $12,4 \%$ de la population féminine, $65.2 \%$ des femmes qui ont répondu au questionnaire sont actives dans le marché de travail, mais un tiers d'entre elles ne se sont pas déclarées aux autorités comme actives.

2 Le sujet et la méthode de ces recherches, qui mettent en question le marché caché du travail, en comparant ses découvertes aux résultats des enquêtes sur le terrain, sont remarquables, car connaître le mécanisme et l'importance des activités économiques hors des statistiques serait une des clés pour se saisir de la société iranienne et de ses particularités.

3 Néanmoins, une réserve quant à la description des caractéristiques de la région et de la population étudiées: les apports de cet article sont minimisés relativement à son investissement.

4 De plus, si le sujet est le marché caché de la main-d'œuvre féminine, il est inutile d'en commenter le taux à plusieurs reprise, par rapport au taux des actifs masculins, car comme chez les femmes, ceux-ci ont également une part qui est dissimulée dans les statistiques : nous ne pouvons pas arriver, à partir des données présentées, à conclure que les actifs masculins sont plus officiellement déclarés.

\section{AUTEURS}

YOKO SUZUKI

Paris 